\title{
SCANNING ELECTRON MICROSCOPIC OBSERVATION OF BASAL CELLS FOLLOWING CORNEAL EPITHELIAL ABRASION
}

\author{
MASAKAZU YAMADA ${ }^{1}$, YUKIHIKO MASHIMA ${ }^{1}$ and KAZUO TSUBOTA ${ }^{2}$ \\ Tokyo and Chiba, Japan
}

\begin{abstract}
SUMMARY
By desquamating single layers of corneal epithelial cells by digitonin, we attempted to observe the basal cell layer of corneal epithelium during wound healing by scanning electron microscopy. Central corneal deepithelisation (diameter 7.0 $\mathrm{mm}$ ) was performed on rabbit eyes. Animals were killed following healing periods of up to 14 days. Half the eyes were treated with digitonin to expose the basal cell layer, and the other half were left untreated to preserve the superficial layer. In non-wounded controls, basal cells were observed as small and columnar-shaped cells. In experimental animals, on day 3 the superficial cells as well as the underlying basal cells were elongated and enlarged. On day 7 , the basal cells became columnar in shape, but remained large. Both superficial cells and basal cells returned to normal on day 14 . This technique allowed us to observe the morphological reconstruction process of basal cells by scanning electron microscopy.
\end{abstract}

Basal cells in the corneal epithelium are known to play a crucial role in the maintenance and the regeneration of corneal epithelial cell layers. Even in a normal, steady state their mitotic activity ${ }^{1-3}$ and their adhesions to the basement membrane ${ }^{4,5}$ are essential for maintaining a normal corneal epithelium. Basal cells are thought to be transient amplifying cells which are rapid cycling and can amplify cell mass effectively by limited rounds of mitosis. ${ }^{6}$ When the corneal epithelium is wounded, they proliferate together with stem cells located in the basal cell layer of the limbus. ${ }^{7-10}$ Although the origin of the leading edge cells has been controversial, ${ }^{11-14}$ basal cells are reported to have a capability for cellular migration. ${ }^{6,13,14}$ Re-formation of hemidesmosomes is

From: ${ }^{1}$ Department of Ophthalmology, Keio University School of Medicine, Tokyo, Japan; and ${ }^{2}$ Department of Ophthalmology, Tokyo Dental College, Chiba, Japan.

Correspondence to: Masakazu Yamada, MD, Department of Ophthalmology, Keio University School of Medicine, 35 Shinanomachi, Shinjuku-ku, Tokyo, Japan 160. important in the process of wound healing. ${ }^{4,5,15}$ If there is damage to the basement membrane, basal cells are responsible for its regeneration. ${ }^{16,17}$ These findings have been accumulated from studies by numerous investigators. However, the reconstruction process of basal cells has been studied mainly by cross-sectional histological methods.

Scanning electron microscopy (SEM) is another technique in histology and has been used to demonstrate morphological features in regenerating corneal epithelium. ${ }^{11-13,18-20}$ However, it has not been used for the observation of basal cells because its application is usually limited to observing the surface microanatomy of the object. In this study, we tried to observe by SEM the basal cell layer of corneal epithelium during wound healing. For this purpose, single layers of apically exposed corneal epithelial cells were desquamated by the use of digitonin. ${ }^{21}$ Repeated application of digitonin resulted in the exposure of underlying basal cells. The images of basal cells at various stages of wound healing were compared with those of superficial cells.

\section{MATERIALS AND METHODS}

All procedures were performed according to the ARVO Resolution on the Use of Animals in Research. Sixteen albino rabbits weighing $2-3 \mathrm{~kg}$ were tranquillised by intramuscular injections of xylazine hydrochloride $(10 \mathrm{mg} / \mathrm{kg})$ and ketamine $(20 \mathrm{mg} / \mathrm{kg})$. Corneas were anaesthetised by the topical administration of oxybuprocaine chloride. Central epithelial abrasions, $7 \mathrm{~mm}$ in diameter, were produced on both eyes with $n$-heptanol as described by Cintron $e t$ al. $^{22}$ Immediately after the epithelial abrasions, the corneas were stained with $0.5 \%$ fluorescein sodium to visualise the epithelial defects and photographed by a SC-1200 slit lamp camera (Kowa, Tokyo, Japan).

The wounds were allowed to heal for designated periods of $1,3,7$ or 14 days ( 8 eyes from 4 rabbits in 


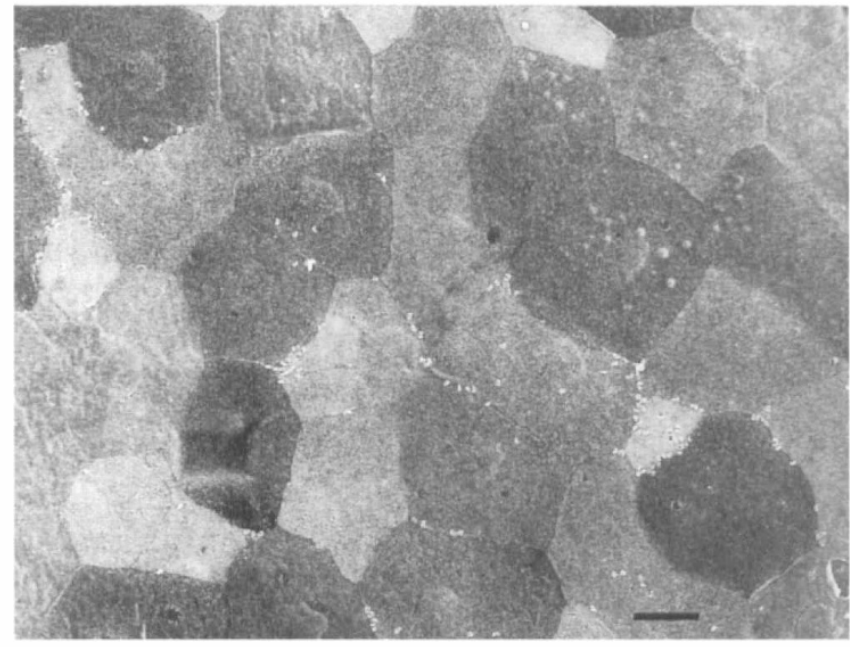

(a)

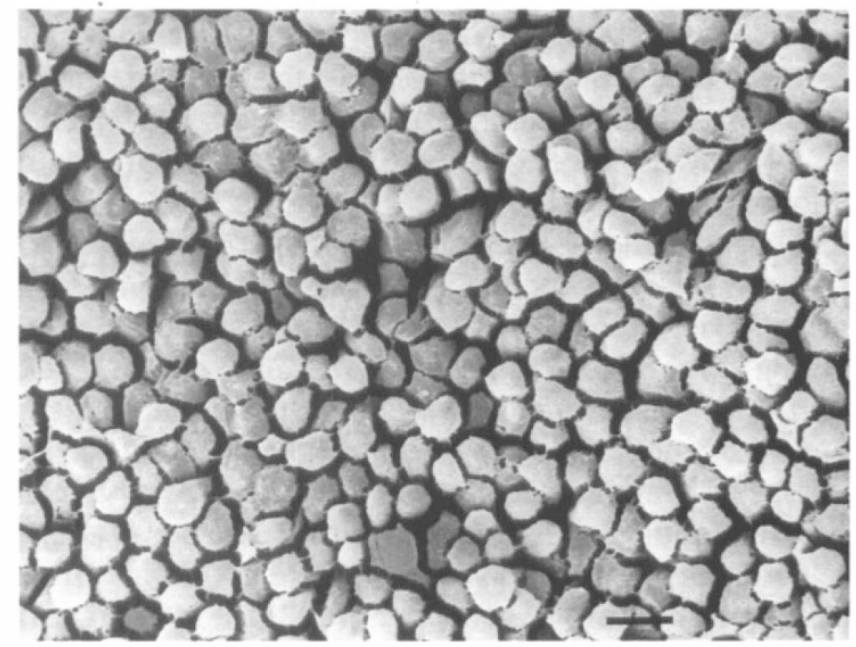

(b)

Fig. 1. Scanning electron micrographs of (a) the superficial cell layer and (b) the basal cell layer in normal rabbit corneal epithelium. Note in (b) that cells are small, round and columnar-shaped. Scale bar represents $10 \mu \mathrm{m}$.

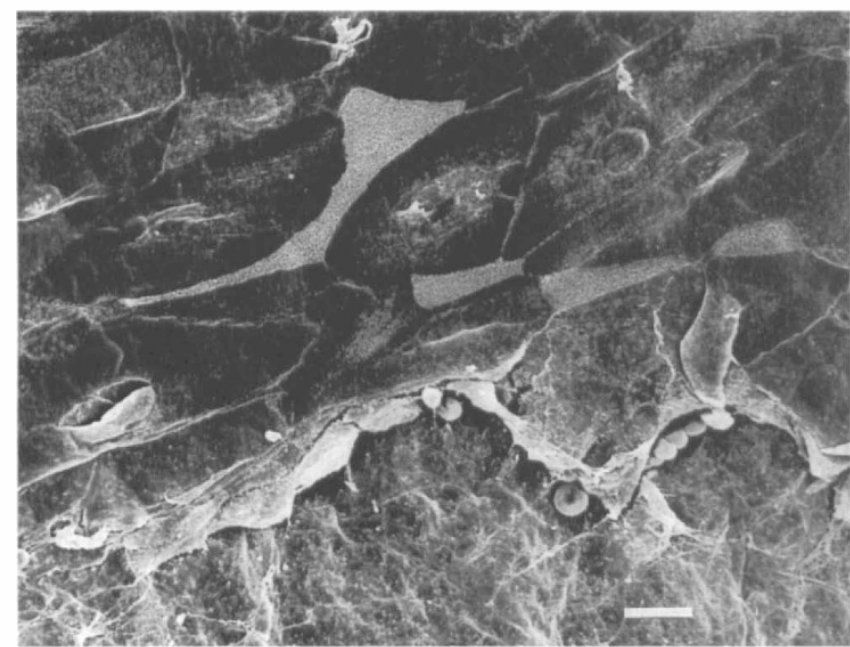

(a)

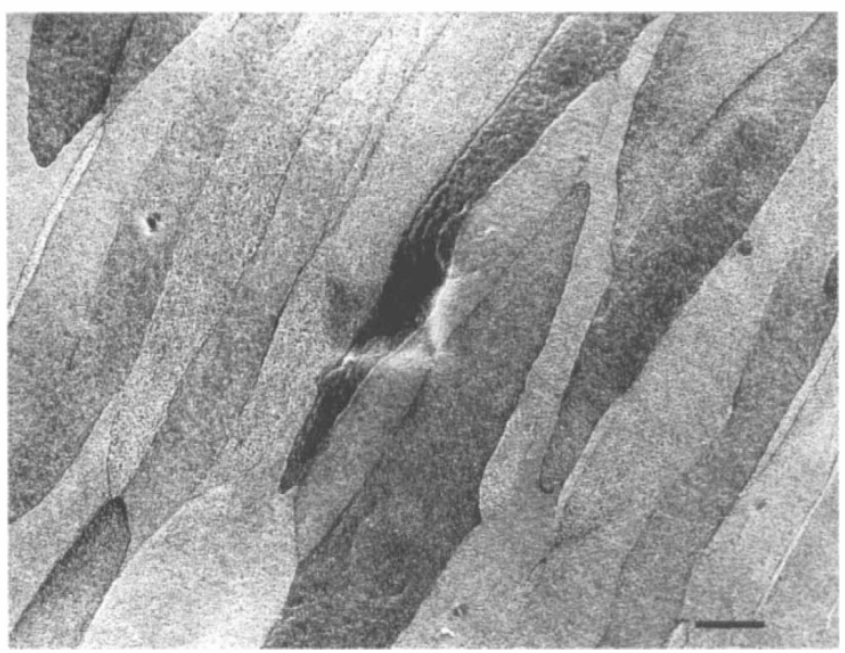

(c)

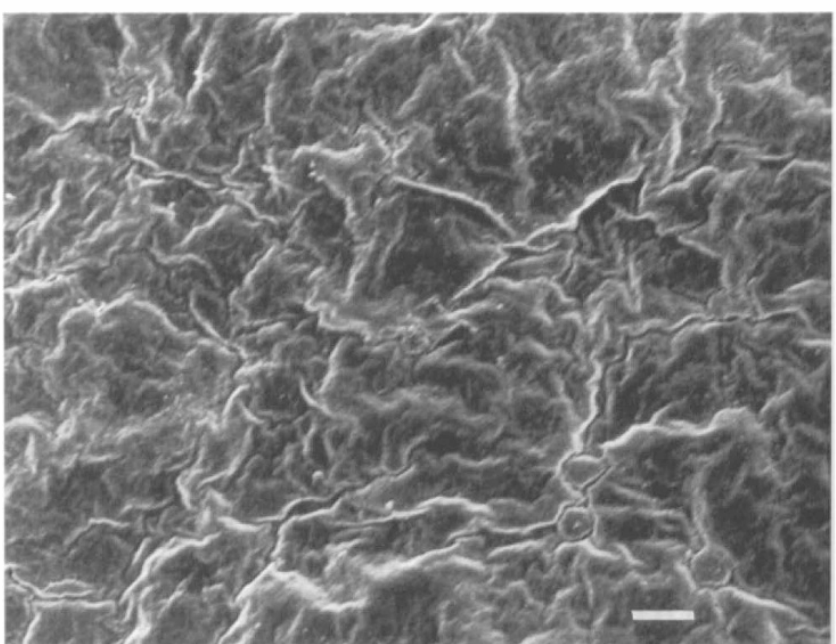

(b)

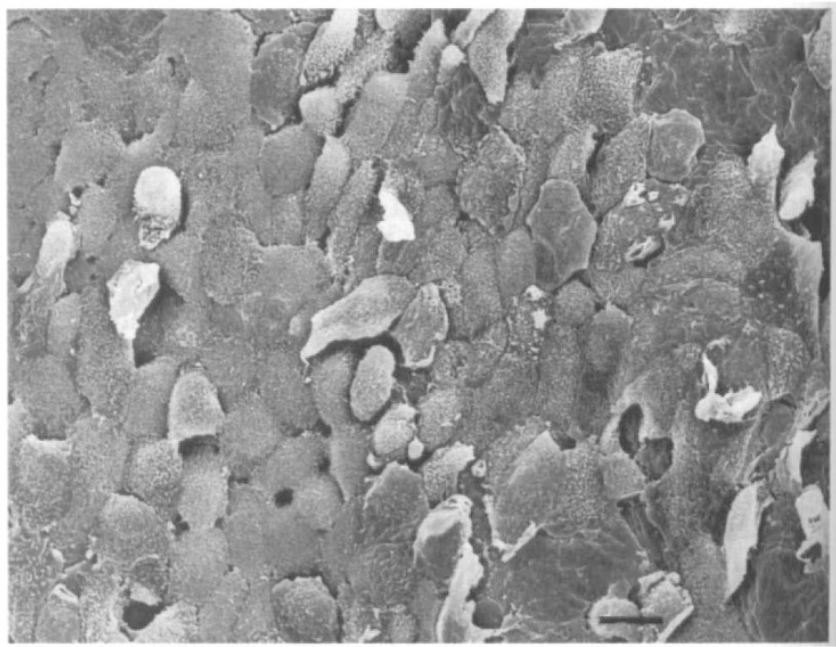

(d)

Fig. 2. Scanning electron micrographs of corneal epithelium during wound healing. On day 1 after abrasion (a) the marginal cells are elongated, and the basement membrane $(b)$ is exposed after a single digitonin treatment. On day $3(c)$, the superficial cell layer consists of large, spindle-shaped cells, and basal cells $(d)$ are apparently flat and large. Some cells look elongated. 


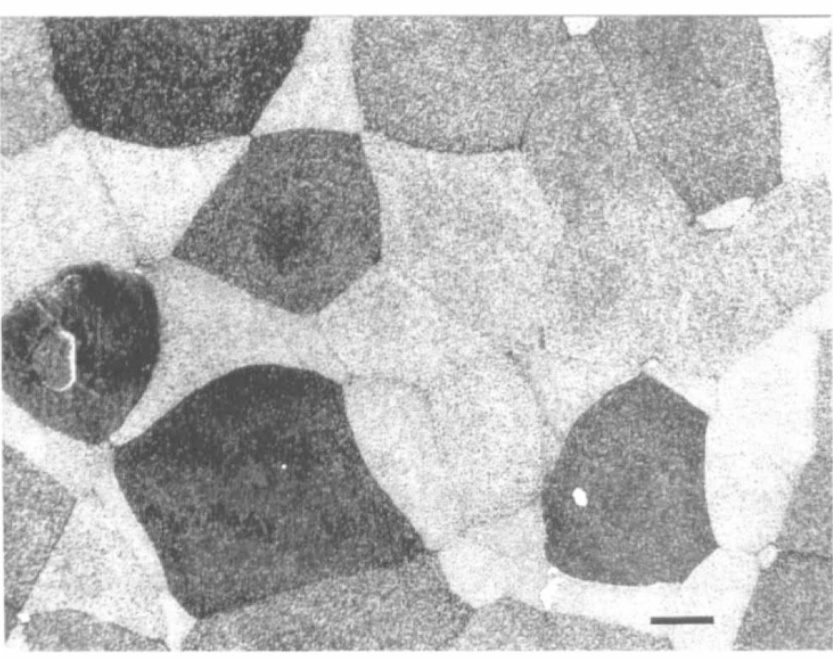

(e)

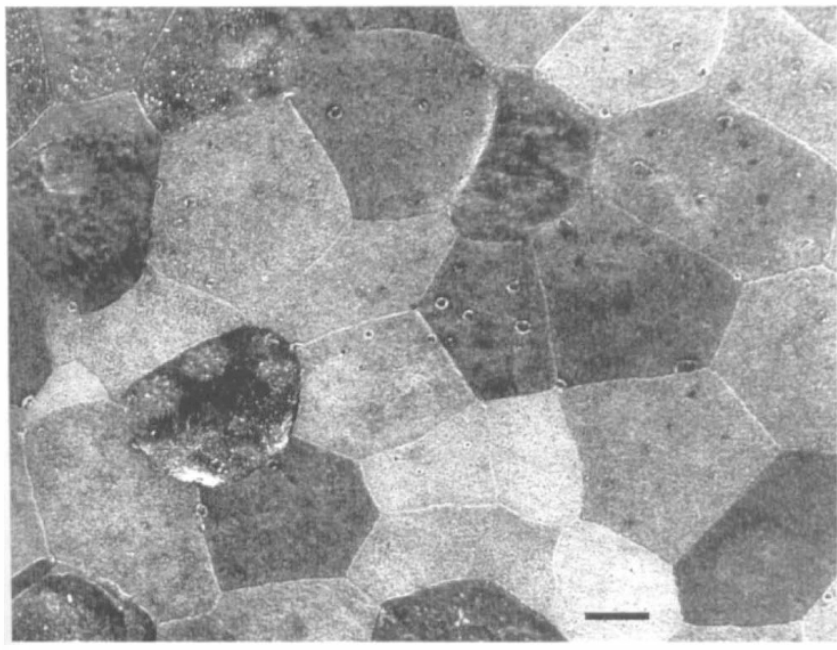

(g)

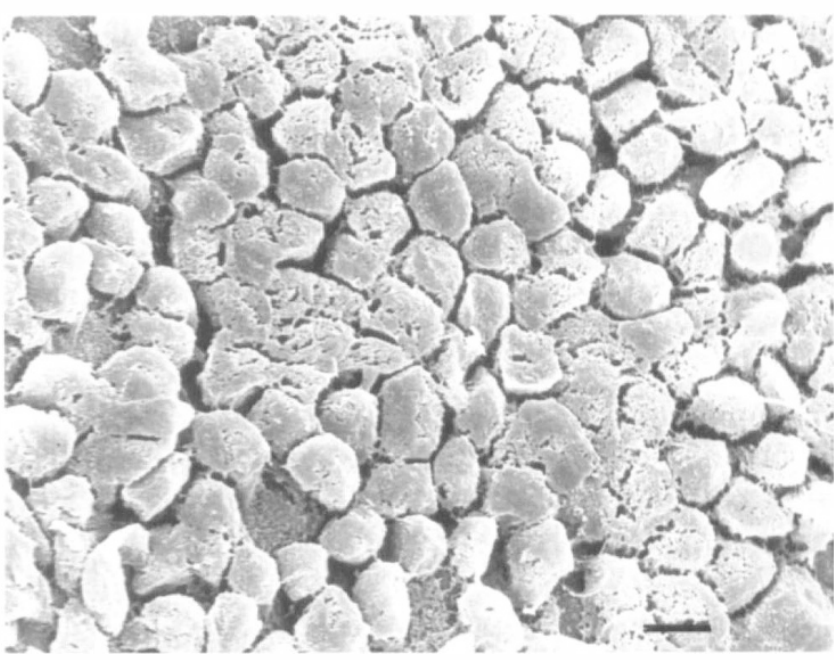

(f)

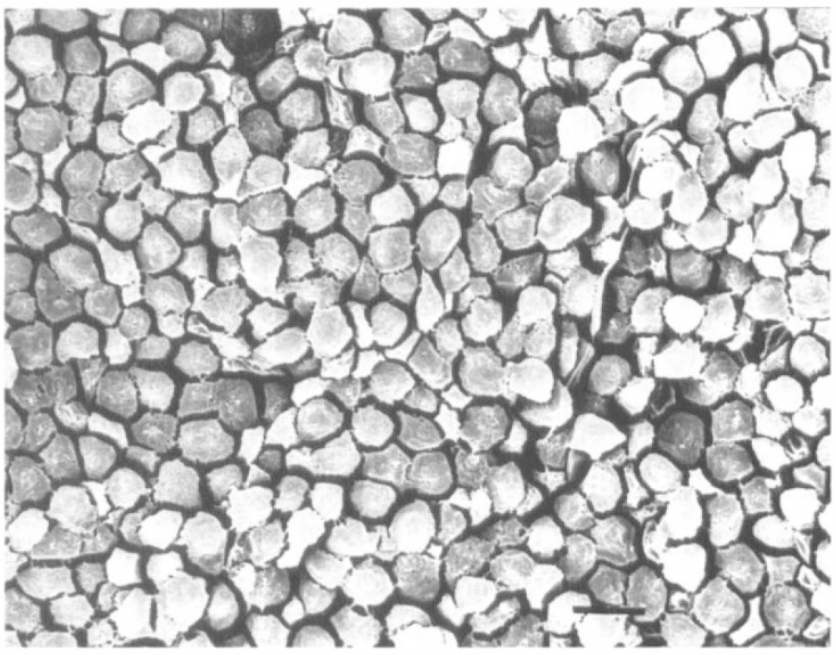

(h)

Fig. 2 (contd). On day 7, both superficial cells (e) and basal cells (f) are still large in size. On day 14, no abnormalities are seen in the superficial cell layer $(g)$ and the basal cell layer $(h)$. Scale bar represents $10 \mu m$.

each group). The remaining epithelial wounds were checked with fluorescein sodium staining. Rabbits were then killed by an intravenous injection of sodium pentobarbital. Eight non-wounded eyes from 4 rabbits served as controls.

The right eye of each rabbit was treated with digitonin to exfoliate superficial and wing cell layers and to expose the basal cell layer for observation by SEM. The left eye was used for SEM observation of the superficial cell layer. The right eyes were enucleated and kept in a humid chamber. The left eyes were flooded with $2.0 \%$ glutaraldehyde in 100 $\mathrm{mM}$ sodium cacodylate, $\mathrm{pH}$ 7.4, for a few minutes, followed by enucleation.

Digitonin treatments were performed as described by Sokol et al. ${ }^{21}$ In brief, the corneas were exposed to $20 \mu \mathrm{M}$ digitonin in saline, followed by staining devitalised cells with $0.4 \%$ trypan blue solution for 2 minutes. The eyes were then washed with saline and incubated in a 1:1 mixture of Dulbecco's modified Eagle's medium and Ham's F-12, buffered with $25 \mathrm{mM} \quad N$-2-hydroxy-ethylpiperazine- $N^{\prime}-2$ ethane sulphonic acid, $\mathrm{pH} 7.4$, until a layer of trypan-blue-stained cells detached spontaneously from the corneal surface. From our preliminary experiments, we found that corneas of the controls, 7 and 14 days after wounding, required three applications of digitonin to expose the basal cell layer. Corneas of eyes 3 days after wounding were treated with digitonin twice, and those of eyes 1 day after wounding, once. When digitonin was applied to these corneas one more time, the basement membrane was exposed. The periods of digitonin treatment were 8 minutes for the first application, 14 minutes for the second, and a combination of 14 minutes and 8 minutes for the third.

Eyeballs were fixed in $2.0 \%$ glutaraldehyde in 100 $\mathrm{mM}$ sodium cacodylate for 30 minutes. Corneas were then excised around the limbus, cut in half and placed in a vial of the same fixative for 2 hours at 
$4{ }^{\circ} \mathrm{C}$. Fixed specimens were post-fixed in buffered $1 \%$ osmium tetroxide for 1 hour, dehydrated in graded ethanol and critical-point dried at $42{ }^{\circ} \mathrm{C}$. The tissues were coated with a light coating of gold/palladium alloy and examined using a Hitachi S-4000 SEM operating at $15 \mathrm{kV}$.

\section{RESULTS}

All epithelial defects healed in a similar fashion. Complete re-epithelisation was achieved by day 3 in most cases. As viewed under a slit lamp biomicroscope, the corneas seemed to return to normal by day 7 .

In controls, the superficial cell layer consisted of polygonal cells (Fig. 1a). On the other hand, the basal cell layer consisted of small, columnar-shaped cells which showed a relatively uniform contrast (Fig. 1b). In some parts of the specimen we occasionally found the transitional portion from the exposed basement membrane and the remaining single cell layer. In other parts, we found a layer of squamous and polygonal cells (possibly suprabasal cells) remaining. Some of the underlying basal cells were seen through them. These columnar-shaped cells were located directly on the basement membrane and their morphological features are distinctly different from the overlying cells. These findings enabled us to identify the basal cells of normal corneal epithelium. In the case of wounded cornea, the identifications of basal cells were performed on the basis of the relationship between the cells and the basement membrane.

Morphological changes in both superficial and basal cells are shown in Fig. 2. One day after wounding, the wound margin was surrounded by flattened and elongated cells (Fig. 2a). Cytoplasmic ruffling and filopodia extending from the free edges to the basal lamina were frequently seen at high magnification. Following a single application of digitonin, these cells were not seen and the basement membrane was exposed (Fig. 2b). Three days after wounding, all denuded areas were covered with regenerating epithelium, their outer surface consisting of enlarged and elongated cells (Fig. 2c). After a single application of digitonin, cells located on the basement membrane, which were thought to be regenerating basal cells, were exposed (Fig. 2d). These cells were apparently larger in size than those of controls. They were flat and polygonal in shape, and some cells looked elongated just like the superficial cells. The regenerating epithelium consisted of five or six cell layers on day 7 according to the cross-sectional observation (data not shown). SEM observations of the superficial cells revealed that they became polygonal in shape, but remained large in size (Fig. 2e). The basal cells, which were exposed by digitonin, still looked flat and large (Fig. 2f). SEM images of superficial cells and basal cells on day 14 are shown in Fig. $2 \mathrm{~g}$ and h. Both images showed no differences compared with controls.

\section{DISCUSSION}

The morphological appearance of regenerating corneal epithelial cells has been studied intensively using SEM. ${ }^{11-13,18-20}$ Previous studies have shown characteristic changes in migrating epithelial cells such as membrane ruffling, filopodia formation, flattening, and elongation in cell shape. However, one limitation of SEM was that only the surface of the cornea, the superficial cell layer of the corneal epithelium, was observable except for the basal cells at the wound edge. Once regenerating epithelial cells stratified, morphological changes of the underlying epithelial cells could not be detected by this method. Therefore, the reconstruction processes of basal cells have been studied using light and transmission electron microscopy. $1,2,4,7-10,14-17,20$ In the present study, a method of desquamating single layers of apically exposed corneal epithelial cells ${ }^{21}$ enabled us to see by SEM the reconstruction process of basal cells during wound healing.

In interpreting the results obtained in the present study, the presence of artefacts should be taken into account. It is conceivable that some of the microanatomy was generated by the treatment with digitonin or the fixation with glutaraldehyde. ${ }^{23}$ For example, intercellular spaces between basal cells were occasionally seen in specimens treated with digitonin. The contraction of tissue, which occurs during fixation, and the tilt angle of the scanning electron microscope might be sources of error in evaluating the cell size. ${ }^{24}$ However, it is reported that the overall devitalisation-exfoliation process had no overt effect on the morphology of the remaining tissue. ${ }^{21}$ All specimens were fixated in the same way, and observed by SEM at a fixed tilt angle.

In the non-wounded controls, basal cells were observed as small, round, columnar-shaped cells. This image obtained by SEM suggests that basal cells in normal condition are morphologically uniform. Basal cells in regenerating corneal epithelium showed remarkable changes on days 3 and 7 after wounding. On day 3, the surface of regenerating epithelium was occupied with elongated, spindleshaped cells. At the same time, the underlying basal cells were enlarged in size and somewhat flattened and elongated in shape. On day 7 post-wounding, superficial cells became polygonal in shape, but remained enlarged in size. The basal cells also looked round or polygonal in shape, but large in size. These increases in cell areas may aid the rapid coverage of the defect. The present study also indicates that the morphological reconstruction of superficial cells occurs simultaneously with that of 
basal cells. Although a decrease in the number of basal cells occupying a unit length of healing epithelium is known from cross-sectional observations using light microscopy, ${ }^{14}$ our study clearly shows these reconstructive processes by SEM.

Several investigators including ourselves have reported specular microscopic observations of corneal epithelium. ${ }^{25-31}$ This observation technique enables the detection of subtle changes in the epithelium in vivo at the cellular level. It is thought that the appearance of spindle-shaped cells and the enlargement of the cell surface area are characteristic features of abnormal corneal epithelium. ${ }^{30}$ As these patterns are seen in patients with various corneal disorders such as keratoconus, ${ }^{27,30}$ post-penetrating keratoplasty, ${ }^{30}$ and extended wear of soft contact lenses, ${ }^{29-31}$ it is thought that these changes might be an indicator of wound healing. ${ }^{30}$ In fact, both spindleshaped cells and enlarged cells were observed by specular microscopy in the rabbit cornea during wound healing. ${ }^{28}$ However, the change in basal cells and its relationship to the change of superficial cells remain unclear, because specular microscopy usually allows visualisation of only the superficial cell layer of corneal epithelium. As an image of specular microscopy is reported to have a good correspondence with that of SEM, ${ }^{26,27}$ our results may provide additional information for better interpretation and understanding of various corneal disorders.

Recently, another method capable of observing corneal epithelial cells in vivo, tandem-scanning microscopy, has been reported. ${ }^{32-37}$ It is stated that not only the superficial cell layer but also the wing and the basal cell layer can be observed by this technique. ${ }^{34-36}$ Indeed, Tomii et al. ${ }^{37}$ reported the enlargement of basal cells in patients with keratoconus $^{37}$ and in aphakic extended soft contact lens wearers. ${ }^{38}$ They reported the appearance of spindleshaped cells and large cells in the superficial cell layer of the patients with these disorders. Their results seem to correlate well with ours. Our methodology can be adopted to confirm these findings obtained from tandem-scanning confocal microscopy. We believe that this method can provide valuable information toward a better understanding of the wound healing process and the various disorders of corneal epithelium.

Key words: Basal cell, Corneal epithelium, Scanning electron microscopy, Wound healing.

\section{REFERENCES}

L. Lamprecht J. Symmetric and asymmetric cell division in rat corneal epithelium. Cell Tissue Kinet 1990;23: 203-16.

2. Haaskjold E, Refsum H, Refsum SB, Bjerknes R. Cell kinetics of rat corneal epithelium. APMIS 1992;100: 1123-8.

3. Sharma A, Coles WH. Kinetics of corneal epithelial maintenance and graft loss. Invest Ophthalmol Vis Sci 1989;30:1962-71.

4. Buck RC. Hemidesmosomes of normal and regenerating mouse corneal epithelium. Virchows Arch Cell Pathol 1982;41:1-16.

5. Gipson IK. Adhesive mechanisms of the corneal epithelium. Acta Ophthalmol (Copenh) 1992; 70(Suppl):13-7.

6. Tseng SCG. Concept and application of limbal stem cells. Eye 1989;3:141-57.

7. Hanna C. Proliferation and migration of epithelial cells during corneal wound repair in the rabbit and the rat. Am J Ophthalmol 1966;61:55-63.

8. Håskjold E, Bjerkenes, Refsum SB. Cell kinetics during healing of corneal epithelial wounds. Acta Ophthalmol (Copenh) 1989;67:174-80.

9. Sandvig KU, Haaskjold E, Bjerkenes R. Regeneration of the rat corneal epithelium after injury: a cell kinetic study comparing the reaction after abrasions made mechanically and with $n$-heptanol. Acta Ophthalmol (Copenh) 1991;69:717-22.

10. Kitazawa T, Kinoshita S, Fujita K, Araki K, Watanabe $\mathrm{H}$, Ohashi Y, Manabe R. The mechanism of accelerated corneal epithelial healing by human epidermal growth factor. Invest Ophthalmol Vis Sci 1990;31: 1773-8.

11. Buck RC. Cell migration in repair of mouse corneal epithelium. Invest Ophthalmol Vis Sci 1979;18:767-84.

12. Brewitt H. Sliding of epithelium in experimental corneal wounds: a scanning electron microscopic study. Acta Ophthalmol (Copenh) 1979;57:945-58.

13. Pfister RR. The healing of corneal epithelial abrasions in the rabbit: a scanning electron microscope study. Invest Ophthalmol Vis Sci 1975;14:648-61.

14. Cintron C, Kublin CL, Covington H. Quantitative studies of corneal epithelial wound healing in rabbits. Curr Eye Res 1981/1982;1:507-16.

15. Fujikawa LS, Foster CS, Gipson IK, Colvin RB. Basement membrane components in healing rabbit corneal epithelial wounds: immunofluorescence and ultrastructural studies. J Cell Biol 1984;98:128-38.

16. Gipson IK, Spurr-Michaud S, Tisdale A, Kenough M. Reassembly of the anchoring structures of the corneal epithelium during wound repair in the rabbit. Invest Ophthalmol Vis Sci 1989;30:425-34.

17. Hirst LW, Kenyon KR, Fogle JA, Hanninen L., Stark WJ. Comparative studies of corneal surface injury in the monkey and rabbit. Arch Ophthalmol 1981;99: 1066-73.

18. Kuwabara T, Perkins DG, Cogan DG. Sliding of the epithelium in experimental corneal wounds. Invest Ophthalmol Vis Sci 1976;15:4-14.

19. Haik BG, Zimmy ML. Scanning electron microscopy of corneal wound healing in the rabbit. Invest Ophthalmol Vis Sci 1977;16:787-96.

20. Crosson CE, Klyce SD, Beuerman RW. Epithelial wound closure in the rabbit cornea: a biphasic process. Invest Ophthalmol Vis Sci 1986;27:464-73.

21. Sokol JL, Masur SK, Asbell PA, Wolosin JM. Layerby-layer desquamation of corneal epithelium and maturation of tear-facing membranes. Invest Ophthalmol Vis Sci 1990;31:294-304.

22. Cintron C, Hassinger L, Kublin CL, Friend J. A simple method for the removal of rabbit corneal epithelium utilizing $n$-heptanol. Ophthalmic Res 1979;11:90-6.

23. Doughty MJ. On the evaluation of the corneal epithelial surface by scanning electron microscopy. Optom Vis Sci 1990;67:735-56.

24. Doughty MJ. Scanning electron microscopy study of 
cell dimensions of rabbit corneal epithelium surface. Cornea 1991;10:149-55.

25. Lohman LE, Rao GN, Aquavella JV. Normal human corneal epithelium: in vivo microscopic observations. Arch Ophthalmol 1982;100:991-3.

26. Lohman LE, Rao GN, Tripathi RC, Tripathi BJ, Aquavella JV. In vivo specular microscopy of edematous human corneal epithelium with light and scanning electron microscopic correlation. Ophthalmology 1982; 89:621-9.

27. Wong S, Rodrigues MM, Blackman HJ, Guimaraes R, Lemp MA. Color specular microscopy of disorders involving the corneal epithelium. Ophthalmology 1984; 91:1176-83.

28. McFarland JL, Laing RA, Oak SS. Specular microscopy of corneal epithelium. Arch Ophthalmol 1983; 101:451-4.

29. Lemp MA, Gold JB. The effects of extended-wear hydrophilic contact lenses on the human corneal epithelium. Am J Ophthalmol 1986;101:274-7.

30. Tsubota K, Yamada M, Naoi S. Specular microscopic observation of human corneal epithelial abnormalities. Ophthalmology 1991;98:184-91.

31. Tsubota K, Yamada M. Corneal epithelial alterations induced by disposable contact lens wear. Ophthalmology 1992;99:1193-6.

32. Lemp MA, Dilly PN, Boyde A. Tandem-scanning (confocal) microscopy of the full-thickness cornea. Cornea 1985/1986;4:205-9.

33. Masters BR, Paddock S. In vitro confocal imaging of the rabbit cornea. J Microsc 1990;158:267-74.

34. Jester JV, Andrews PM, Petroll WM, Lemp MA, Cavanagh HD. In vivo, real time confocal imaging. J Electron Microsc Tech 1991;18:50-60.

35. Jester JV, Petroll WM, Garana RM, Lemp MA, Cavanagh HD. Comparison of in vivo and ex vivo cellular structure in rabbit eyes detected by tandem scanning microscopy. J Microsc 1992;165:169-81.

36. Masters BR. Specimen preparation and chamber for confocal microscopy of the ex vivo eye. Scanning Microsc 1993;7:645-51.

37. Tomii S, Kinoshita S, Nishida K. Observation of corneal epithelial basal cells in the patients with keratoconus by tandem scanning confocal microscope. Atarasii Ganka 1993;10:1369-71.

38. Tomii S, Kinoshita S, Nishida K. Observation of corneal epithelial basal cells in soft contact lens extended wearers by tandem scanning confocal microscope. J Jpn CL Soc 1993;35:163-6. 